\title{
Aesthetic Improvement of Burn Scar by Tangential Excision and Thin Split Thickness Skin Graft
}

\author{
So-Min Hwang, Jang Hyuk Kim, \\ Hyung-Do Kim, Yong-Hui Jung, \\ Hong-Il Kim
}

Aesthetic, Plastic \& Reconstructive Surgery Center Good Moonhwa Hospital, Busan, Korea

No potential conflict of interest relevant to this article was reported.
Background Burn injuries of the extremity can result in cosmetically offensive appearance. Postburn scar can improve by the combination of tangential excision and thin split-thickness skin graft.

Methods From January 2005 and December 2012, 17 patients (10 males and 7 females) with postburn scar of the extremity underwent the combined techniques. The median time from initial injury to surgery was 66.2 months (range: 11-288 months). In the operation, burn scar was excised until viable dermis could be observed using electrical dermatome, after which thin split thickness skin graft was performed.

Results Tangential excision and thin split thickness skin graft gave excellent grafting results without the need of reoperation. Depigmentation in the majority of patients were recovered within a year by the operation of thin split thickness skin graft. Recovery of range of motion and cosmetic results were good in all patients.

Conclusions Tangential excision and thin split thickness skin graft are a good way of the reconstruction of deformed and depigmented skin from burns on extremity.

Keywords Postburn scar, Tangential excision, Thin skin graft

\section{INTRODUCTION}

It has been known that the post-burn scar may cause symptoms including pigmentation, pruritus, pain, and contracture, and result in psychosocial depression of individuals due to the loss of physical functions and dysmorphia depending on the location and severity of the burn scar, leading to substantial disruption in social life. In the particular case of hand and extremities where burn occurs frequently, although there have been a great deal of literature concerning the recovery of functional loss due to the burn contracture, the interest in the aesthetic recovery of the burning scar on the hand tends to be gradually increasing lately, reflecting the words "the hand is the secondary face".

Received: Sep 2, 2013 Revised: Oct 19, 2013 Accepted: Oct 21, 2013 Correspondence: So-Min Hwang APRSC, Good Moonhwa Hospital, 119 Beomil-ro, Dong-gu, Busan 601-803, Korea. E-mail: lexusair@gmail.com

http://submit.e-aaps.org/

Copyright (๑) 2013 The Korean Society for Aesthetic Plastic Surgery.

This is an Open Access article distributed under the terms of the Creative Commons Attribution Non-Commercial License (http://creativecommons.org/licenses/by-nc/3.0/) which permits unrestricted non-commercial use, distribution, and reproduction in any medium, provided the original work is properly cited
The aesthetic treatments of the post-burn scar on the hand include tattoo, punch grafting, epidermal graft after dermabrasion, chip skin graft and thin sheet skin graft [1-6]. However, the tattoo generated different skin color, and the simple skin graft may result in regrettable outcomes such as prominent scar around the boundary of the burn site, collapse of skin graft site, donor site scar, and pigmentary degeneration over time.

Accordingly, we aim to confirm the outcomes of the thin splitthickness skin graft with a thickness of less than 8/1,000 inches that was carried out following the tangential excision of burn scar using an electrical dermatome for the aesthetic improvement of the post-burn scar of the hand.

\section{METHODS}

This study was performed on patients who had received the treatments of the tangential excision and the split-thickness skin graft for the aesthetic improvement at our hospital since January 2005 until December 2012. All patients were with the pigmentary degeneration or hypertrophic burn scar after suffering from the burn on the hand. They consisted of 10 males and 7 females, a total of 17 (Table 1). 
Table 1. The data of patients

\begin{tabular}{|c|c|c|c|c|c|c|}
\hline NO & Sex/Age & Scar site & $\begin{array}{l}\text { Scar extent } \\
\left(\mathrm{cm}^{2}\right)\end{array}$ & $\begin{array}{l}\text { Period from burn } \\
\text { injury to operation } \\
\text { (months) }\end{array}$ & $\begin{array}{l}\text { Period from operation } \\
\text { to last follow up } \\
\text { (months) }\end{array}$ & Satisfaction \\
\hline 1 & $F / 34$ & Forearm (volar), Left & 110 & 87 & 13 & very satisfied \\
\hline 2 & $F / 25$ & Hand, Forearm (dorsum), Right & 105 & 93 & 12 & very satisfied \\
\hline 3 & $M / 30$ & Forearm (volar), Right & 143 & 300 & 12 & satisfied \\
\hline 4 & $M / 33$ & Hand (dorsum), Right & 60 & 11 & 30 & very satisfied \\
\hline 5 & $F / 47$ & Tibia (medial side), Right & 30 & 25 & 20 & very satisfied \\
\hline 6 & $\mathrm{M} / 37$ & Hand (dorsum), Left & 16 & 26 & 24 & very satisfied \\
\hline 7 & $M / 20$ & Upper arm (volar side), Right & 140 & 20 & 15 & satisfied \\
\hline 8 & $M / 61$ & Forearm (dorsum), Left & 36 & 41 & 13 & very satisfied \\
\hline 9 & $F / 51$ & Forearm (dorsum), Right & 170 & 360 & 24 & very satisfied \\
\hline 10 & $M / 53$ & Forearm (dorsum), Left & 110 & 23 & 17 & very satisfied \\
\hline 11 & $M / 64$ & Tibia (lateral side), Right & 77 & 17 & 12 & very satisfied \\
\hline 12 & $M / 52$ & Forearm (volar), Left & 70 & 31 & 18 & very satisfied \\
\hline 13 & $F / 32$ & Forearm (dorsum), Left & 88 & 20 & 27 & very satisfied \\
\hline 14 & $F / 56$ & Upper arm (dorsum), Right & 90 & 13 & 20 & satisfied \\
\hline 15 & $M / 55$ & Forearm (dorsum), Left & 66 & 20 & 23 & very satisfied \\
\hline 16 & $M / 19$ & Forearm (volar), Right & 90 & 18 & 18 & very satisfied \\
\hline 17 & $F / 27$ & Upper arm (dorsum), Left & 80 & 21 & 13 & very satisfied \\
\hline
\end{tabular}

As for surgery, the boundary of the burn scar was marked and the scar was tangentially excised using a dermatome up to the point that hemorrhage in the capillaries was observed. With the femoral region as a donor site, the thin split-thickness skin graft was collected using a dermatome at a thickness of 6/1,000-8/1,000 inches matching the dimension of the recipient site generated by the tangential excision. The donor site received a foam dressing and was pressed lightly after its bleeding was stopped by a gauze pre-soaked in 1:100,000 epinephrine. After the collected graft had been grafted on the recipient site, wet-to-dry dressing was conducted to absorb an exudation. The skin graft was checked open on the fifth day, and the patients were asked to avoid the exposure of their affected area to the sun and use a skin wetting agent.

Patients were assessed for four conditions including pigmentation, vascularity, pliability and height through physical examinations on the scar before and after operation, respectively by applying Vancouver Scar Scale (VSS) (Table 2). The level of patients' satisfaction on the surgical site was surveyed after at least 12 months from surgery using questionnaires selecting one of five answers including very satisfied, satisfied, neutral, unsatisfied and very unsatisfied.

\section{RESULTS}

The mean elapsed time between the occurrence of burns and the treatment of the tangential excision and the thin split-thickness skin graft was 66.2 months (11-288 months), and the mean area
Table 2. Vancouver Scar Scale

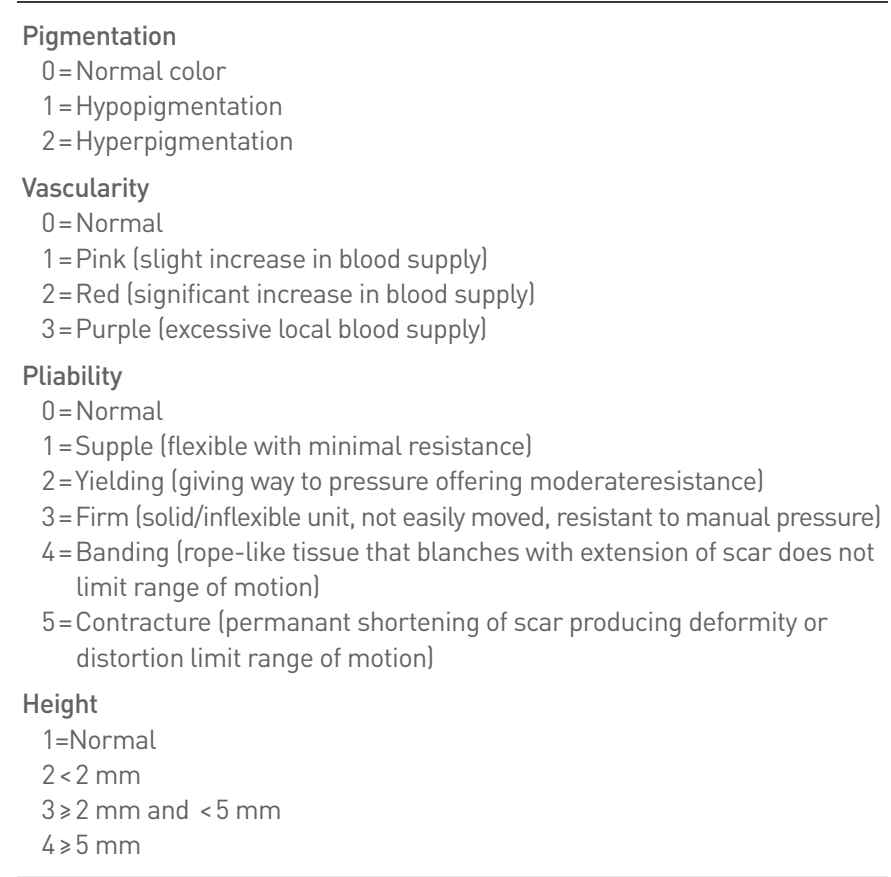

of the burn scars was $87 \mathrm{~cm}^{2}\left(16-170 \mathrm{~cm}^{2}\right)$. After the tangential excision and the thin split-thickness skin graft, all of 17 patients did not need regrafting and other complications were not observed at all. The color of the graft was initially red, but it has gradually changed to a color similar to the surroundings with a good texture, 


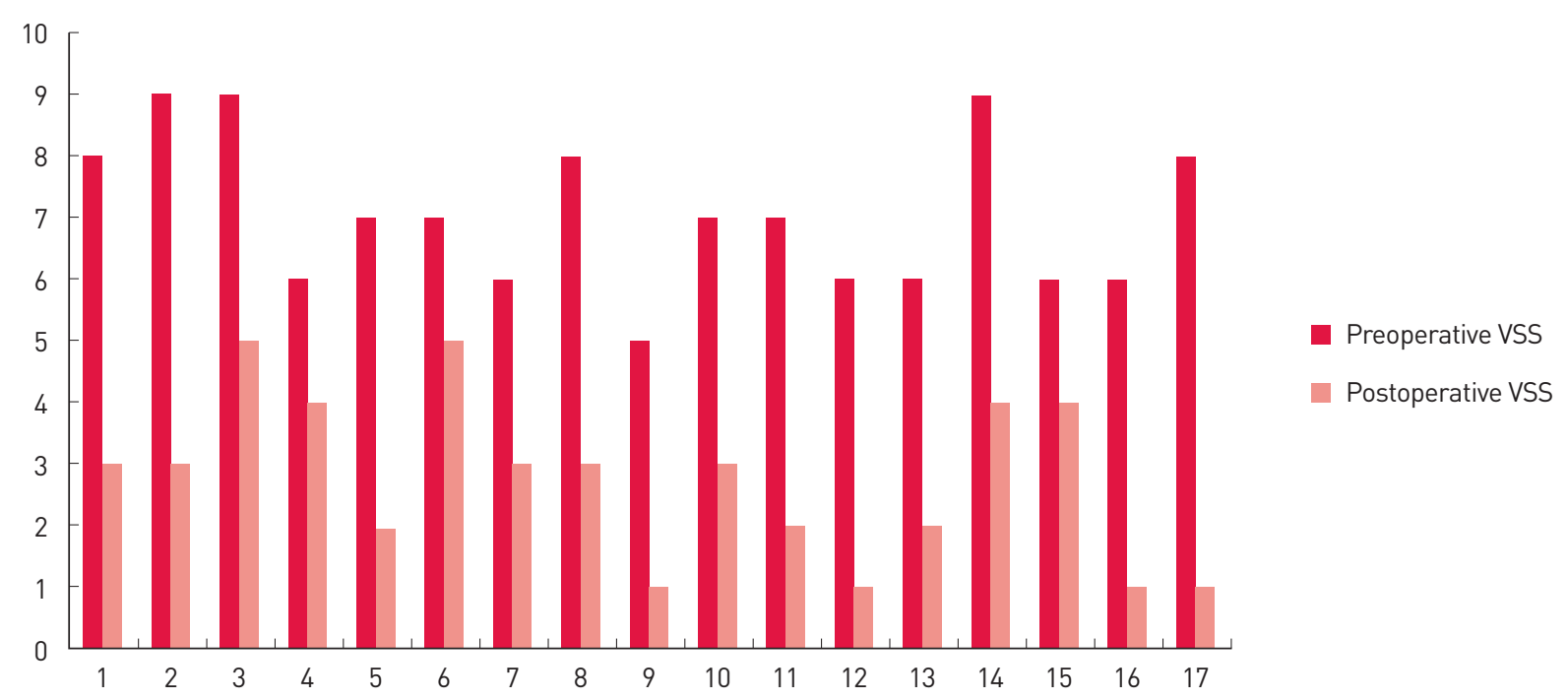

Fig. 1. Results of Vancouver Scar Scale (VSS).

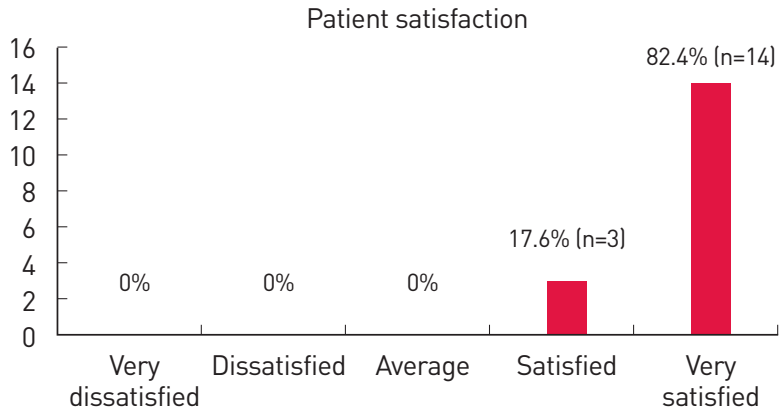

Fig. 2. Patient satisfaction.

which was well maintained in the follow-up progress. The donor site, from which the thin split-thickness skin with a thickness of $6 / 1,000$ to $8 / 1,000$ inches had been collected, also displayed an aesthetically excellent progress.

VSS indicated the improvement of pigmentation in 14 out of 17 patients; vascularity in 7; pliability in 14; and skin thickness in 16 . The total score of the VSS were improved by 4.3 points on average with the lowest improvement of 2 to the highest of 7 in all $17 \mathrm{pa}$ tients (Fig. 1). The period from surgery to the survey on satisfaction was 18.3 months on average with the shortest time of 12 months to the longest of 40 months, and the survey suggested that 14 were very satisfied and 3 were satisfied, indicating that all 17 patients were satisfied with the outcomes (Fig. 2).

\section{Case 1}

A male patient aged 30 with a scar caused by ambustion 25 years ago visited our hospital. A hypertrophic burn scar with the size of $13 \times 11 \mathrm{~cm}$ was observed on the right forearm, and thus the tangential excision using a dermatome was performed, followed by the thin split-thickness skin graft using the thin skin collected from the right femoral region with a thickness of 6/1,000 inches (Fig. 3). After two years from surgery, no scar contracture or hypertrophic scar was observed while it could be clearly seen that the surgery site displayed the aesthetic improvement; the pre-surgery VSS of 8 points (hyperpigmentation: 1, pink vascularity: 1, pliability: 3 and height: 3 ) went down to 5 points in the post-surgery VSS, which was a clear improvement; and his response was also "satisfied" in the patients' satisfaction survey.

\section{Case 2}

A female patient aged 51 visited our hospital with hyperpigmentation caused by ambustion 30 years ago as the chief complaint. A burn scar with the size of $17 \times 10 \mathrm{~cm}$ was observed on the right forearm and thus the tangential excision was performed, followed by the thin split-thickness skin graft using the thin skin collected from the right femoral region with a thickness of 7/1,000 inches (Fig. 4). It could be seen that the surgery site have similar color and outline to those of the surrounding skin at the 1 year time point after surgery.; The pre-surgery VSS of 5 points (pigmentation: 2 , vascularity: 0 , pliability: 2 and height: 1 ) was improved to 1 point in the post-surgery VSS, indicating the improvement in skin color and pliability, and her response in the patients' satisfaction survey was "very satisfied".

\section{DISCUSSION}

In the case of the post-burn scar on the hand, although functional recovery is most important, aesthetic outcomes are equally important since the hand is a frequently exposed body part, next to the face in daily life [7].

There are various aesthetic treatments for the post-burn scar on 

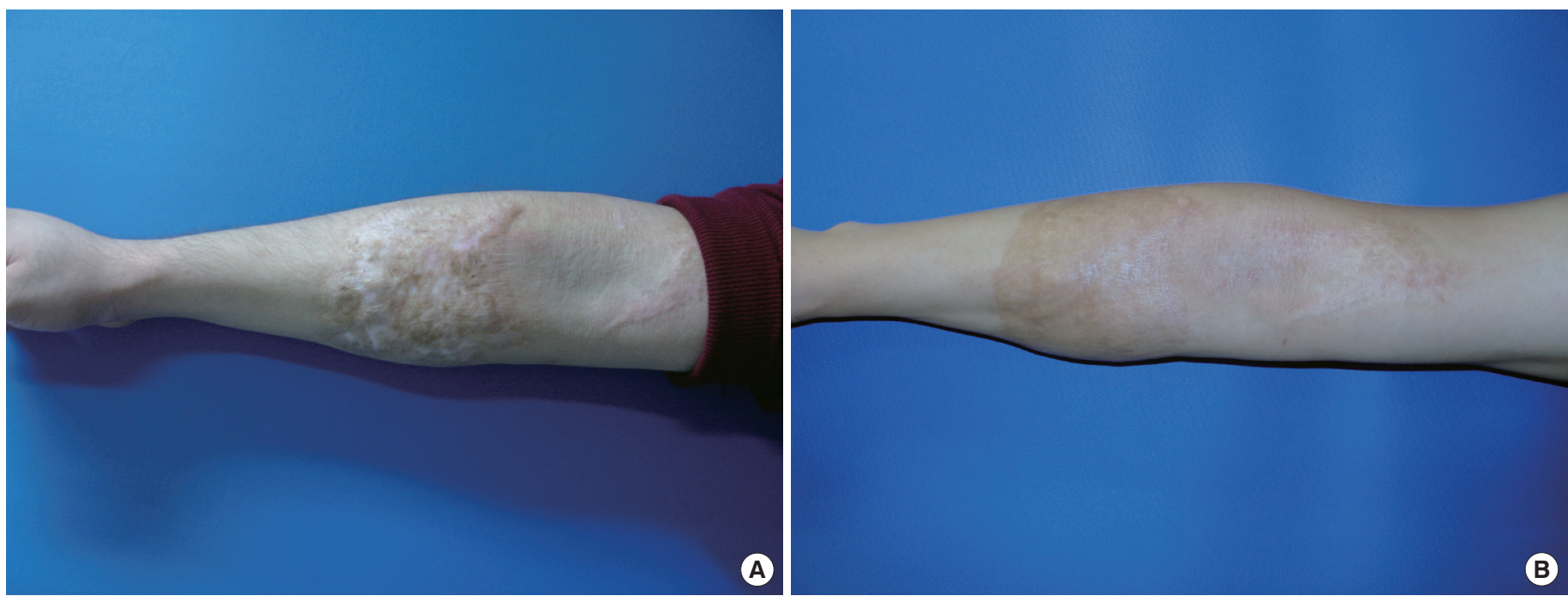

Fig. 3. (A) A 30-year-old man with a hypertrophic scar on the volar aspect of the right forearm caused by a scald burn 25 years previously. (B) Photograph taken at 2 years after surgery-note the even surface and adequate colored skin of the forearm.
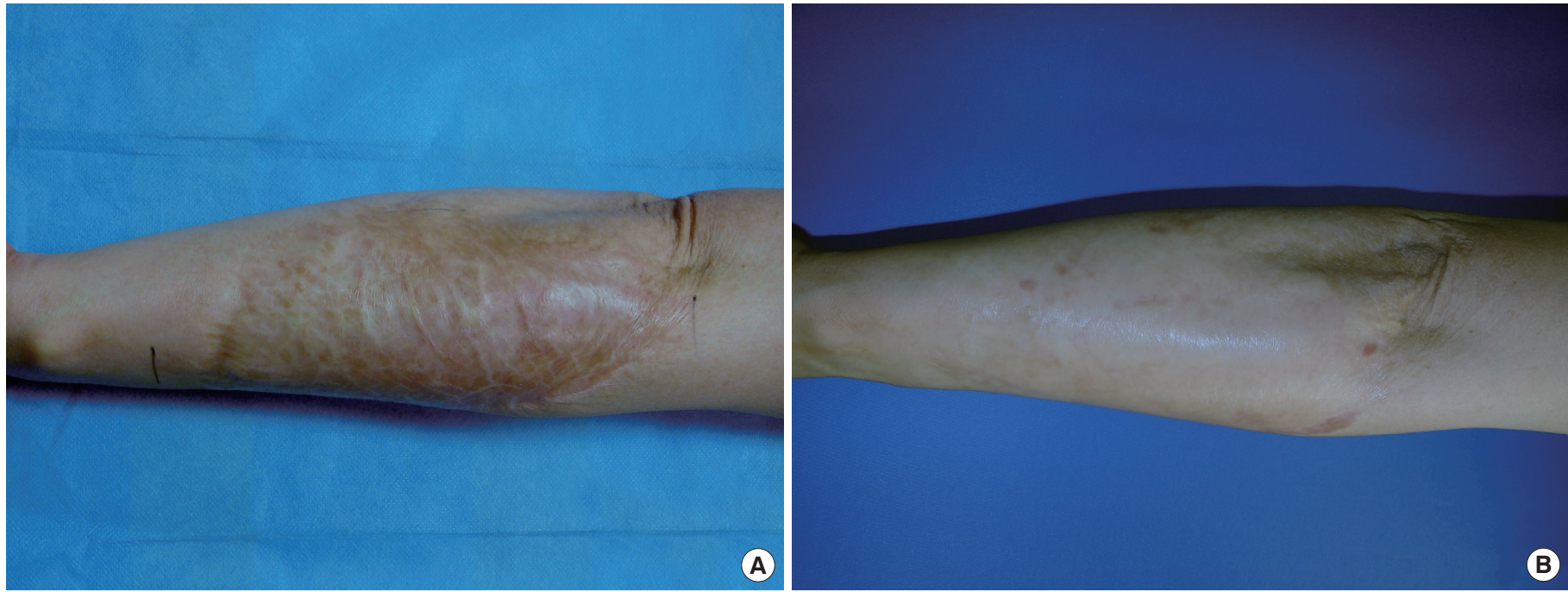

Fig. 4. (A) A 51-year-old woman with a hypertrophic scar on the dorsum aspect of the right forearm caused by a scald burn 30 years previously. (B) Photograph taken at 1 years after surgery-note the even surface and adequate colored skin of the forearm.

the hand including tattoo, punch grafting, dermal overgraft after dermabrasion, chip skin graft and thin sheet skin graft. However, the tattoo has a limitation in recovering the natural skin color and the thick split-thickness skin graft may leave a scar around the boundary between the graft and the surrounding area, and result in a hypertrophic scar on the donor site [1-6]. The dermal overgraft published by Webster in 1954 is a method that the primary split-thickness skin graft is performed on the recipient dermis bed or the denuded scar and after it is healed up, the graft is abraded and the secondary split thickness skin graft is conducted on it [8]. On the other hand, our method is different in that a thinner splitthickness skin graft than the conventional one is used, and the skin grafting is performed only once. The advantages of our method are that surgery is performed only once, donor site morbidity is small due to the thinner graft, and therefore the loss of the tissue is minimal even if the graft is not successful. On the down side, our procedure is difficult to apply the method to the areas where there is bony prominence or scar contracture.

Our method was used for the aesthetic correction of the burn scar, not for the acute treatment phase. The thin split-thickness skin graft was conducted after the burn scar was denuded by the tangential excision up to the thickness at which capillary bleeding was observed. While this could also be used on a hypertrophic burn scar since the scar could be removed using a dermatome, its 
use had limitations in the burn scar contracture. It was ensured that the thickness of the skin graft did not exceed 8/1,000 inches.

The scar tissue could be removed evenly using a dermatome. The advantages are that the surgery time is reduced and the scar can be grated evenly. As disadvantages, the accuracy of a dermatome may be lower than that of a dermabrader in removing the boundary of the scar.

The tangential excision using a dermatome can preserve the panniculus by peeling the burn scars thinly several times iteratively and remove the base epidermal layer containing melanin in the dyspigmented site (skin thickness: 6/1,000 inches). Moreover, it may also offer the shorter surgical time with an easy method [5]. Also it can be carried out several times repetitively if necessary, and reduce the recovery time with the prompt engraftment and shallow damage on the donor site [6].

In this study, the patients did not complain of significant pain at donor sites that had been healed within 1 week, and the longterm observation of the progress showed that the color of donor sites was recovered to that similar to the surrounding normal skin. The recipient site after grafting had an excellent pliability, and since a dyspigmented site or a hypertrophic scar was removed by the tangential excision, and subsequently the thin split-thickness skin was grafted, which helped the repigmentation of the grafted site, the depigmentation could be improved from the initial phase after surgery. Erol and Ataby have reported that the ratio of abnormal hyperpigmentation was $5 \%$ after the thin split-thickness skin graft with a thickness of $0.2-0.3 \mathrm{~mm}$, and suggested that it was caused by the excessive exposure of the skin graft recipient site to the sun $[6,7,9]$. Accordingly, in this study, we could prevent hyperpigmentation from occurring by making patients refrain from exposing the surgical site to the sunlight. In addition, the hypertrophic scar could be prevented by applying the press garment and silicon medication on the skin graft recipient site of patients [1]. While Walton et al. have reported that an inclusion cyst might be generated from the residue of the follicles after the thin splitthickness skin graft, in this study the generation of an inclusion cyst was not observed, and it is considered that since inclusion cysts disappear within 6 months spontaneously $[6,10]$, it would not greatly affect the post-surgery outcomes.

We have assessed the outcomes of the thin split-thickness skin graft after the tangential excision by two methods of the VSS and a patients' satisfaction survey. The VSS was first devised by Sullivan et al. [11] in 1990, which assesses four elements including pigmentation, vascularity, pliability and height. In 2005, Truong et al. [12] suggested that the VSS was useful also in the assessment of scars that were generated after a breast cancer surgery, indicating its generality. As such, this has been accepted as a valid scale of post-surgery scars as well as burn scar. Accordingly, we employed it to assess the outcomes of the surgical methods in this study. Three plastic surgeons participated in the assessment to maintain objec- tivity.

The average VSS has decreased to 2.8 points from 7.1 points after the thin split-thickness skin graft following the tangential excision, which confirmed that the aesthetic outcomes of the burn scar were excellent. The survey that required a response from five answers of very satisfied, satisfied, neutral, unsatisfied and very unsatisfied was performed to assess the patients' subjective satisfaction with aesthetic outcomes on their surgical site, and it indicated that all 17 patients were satisfied: 14 very satisfied and 3 satisfied.

\section{CONCLUSIONS}

Since the hand is a frequently exposed body part, perhaps next to the face in daily life, the aesthetic recovery of burn scar as well as the functional recovery is necessary. The conventional aesthetic treatments of burn scar have various limitations such as differences in skin color, collapse of skin graft site, donor site scar, and pigmentary degeneration. Accordingly, we have carried out the thin split-thickness skin graft after the tangential excision for the aesthetic improvement of the post-burn scar of the hand, which resulted in the substantial improvement in the VSS and the excellent patients'satisfaction. In conclusion, we report that better aesthetic outcomes can be obtained by conducting the thin split-thickness skin grafting following the tangential excision of burn scars on the hand.

\section{REFERENCES}

1. Oh SJ, Kim Y. Combined AlloDerm and thin skin grafting for the treatment of postburn dyspigmented scar contracture of the upper extremity. J Plast Reconstr Aesthet Surg 2011;64:229-33.

2. van der Velden EM, Baruchin AM, Jairath D, et al. Dermatology: A method for permanent repigmentation of achromic burn scars. Burns 1995;21:304-7.

3. Burm JS, Rhee SC, Kim YW. Superficial dermabrasion and suction blister epidermal grafting for postburn dyspigmentation in Asian skin. Dermatol Surg 2007;33:326-32.

4. Kahn AM, Cohen MJ, Kaplan L. Treatment for depigmentation resulting from burn injuries. J Burn Care Rehabil 1991;12:46873.

5. Kahn AM, Cohen MJ. Treatment for depigmentation following burn injuries. Burns 1996;22:552-4.

6. Onur Erol O, Atabay K. The treatment of burn scar hypopigmentation and surface irregularity by dermabrasion and thin skin grafting. Plast Reconstr Surg 1995;85:754-8.

7. Moon SH, Lee SY, Jung SN, et al. Use of split thickness plantar skin grafts in the treatment of hyperpigmented skin-grafted fingers and palms in previously burned patients. Burns 2011;37: 714-20. 
8. Rees TD, Casson PR. The indications for cutaneous dermal overgrafting. Plast Reconstr Surg 1966;38:522-8.

9. Degheidy MM, El-Morsy IH, El-Mulla K. Evaluation of the role of dermabrasion and thin skin grafting in the treatment of burn scar depigmentation. Egypt J Reconstr Surg 2003;27:95-99.

10. Walton RL, Cohn AB, Beahm EK. Epidermal overgrafting improves coloration in remote flaps and grafts applied to the face for reconstruction. Plast Reconstr Surg 2008;121:1606-13.

11. Baryza MJ, Baryza GA. The Vancouver scar scale. An administration tool and its interrater reliability. J Burn Care Rehabil 1995; 16:535-8.

12. Kaartinen IS, Välisuo PO, Alander JT, et al. Objective scar assessment--a new method using standardized digital imaging and spectral modelling. Burns 2011;37:74-81. 